\title{
Forest-bird Species Assemblages in the Lowland Rainforest of Madagas- car: The Effects of Forest Fragmentation Revisited
}

\author{
Jean-Eric Rakotoarisoa*,1,2 and Angelo P. Capparella ${ }^{2}$ \\ ${ }^{1}$ Department of Anthropology, Stony Brook University, Stony Brook, NY 11794, USA \\ ${ }^{2}$ School of Biological Sciences, Illinois State University, Normal, IL 61790, USA
}

\begin{abstract}
Although the eastern lowland rainforest of Madagascar houses a high proportion of endemic birds, little is known about how fragmentation effects and habitat loss specifically impact them. We analyzed published lists of forest birds across several eastern lowland rainforest fragments of three size classes (large: 6,000 ha, medium: 2,000 ha, small: $600 \mathrm{ha})$ and varying distance $(0.45-20 \mathrm{~km})$ from a nearby continuous forest block. Several key species traits were incorporated to elucidate 1) patterns of species loss across forest fragments and the characteristics of lost species; 2) relationships of species richness and composition with fragment size and distance, and the factors that potentially drive these associations; and 3) pattern of nestedness in the resulting species assemblages. At the scale of our study, we found that species' vulnerability to loss was a function of degree of rarity and ecological specialization, such as insectivorous diet and habitat restriction. Fragment size was associated with species richness and composition. However, distance from the remaining continuous forest block and human disturbance, such as selective logging, may also influence their patterns of association. Both ecological factors and sampling effects (passive sampling of the regional species pool) appeared to influence species distribution across our fragments. Although no significant pattern of nested subset was detected among individual fragments, such a pattern is apparent among fragments from the three size classes. We briefly address conservation implications of these findings.
\end{abstract}

Keywords: Endemic, birds, habitat fragmentation, lowland rainforest, Madagascar.

\section{INTRODUCTION}

The alarming rate of deforestation in tropical countries constitutes a major threat to both local and global biodiversity [1]. This issue is especially true for the eastern rainforest of Madagascar, which houses the largest proportion of endemic vertebrate taxa on the island [2, 3]. For birds, this ecosystem harbors the greatest diversity of resident avifauna, housing 179 nesting species (out of the 209 breeding species on the island), among which 89 are endemic [3, 4]. Unfortunately, more than $70 \%$ of the eastern rainforest has been cleared since human arrival some 2,000 years ago, with an average clearance rate of $0.6-1.7 \%$ per year between 1950 and 2000 [5]. Because deforestation mainly occurs at lower elevations $(<800 \mathrm{~m})$ easily accessible to humans $[5,6]$, lowland specialist birds are particularly at risk [4]. However, very little is known about the impacts of the resultant fragmentation of the lowland eastern rainforest on the local avifauna.

Among the studies investigating the effects of forest fragmentation on birds in Madagascar (e.g. [7-10]), only Andriamasimanana et al. [10] examined these effects across large forest fragments (510-6,680 ha). They were also the first to conduct such a study in eastern rainforest sites below

*Address correspondence to this author at the School of Biological Sciences, Illinois State University, Normal, IL 61790, USA;

Tel: 203-589-8814; Fax: 309-438-3722; E-mail: jerakot@ilstu.edu
$800 \mathrm{~m}$ elevation, which we refer to herein as the lowland eastern rainforest. After comparing species lists among forest fragments and larger reference sites, Andriamasimanana et al. [10] found differences in species richness. However, other aspects associated with those differences were not examined, such as the patterns of species vulnerability and the characteristics of the resulting communities as fragment size decreases and fragments are increasingly isolated, as well as the factors (ecological and non-ecological) that potentially drive these patterns. These aspects are important to investigate at this large geographic scale for the following reasons.

First, the eastern lowland rainforest is exposed to tremendous human pressure due to the widespread practice of slash-and-burn agriculture. Given the $2.7 \%$ average human population growth rate on the island [11], deforestation is likely to continue and will force conservationists to rely increasingly on forest fragments (vs. large and continuous forest areas) to maximize conservation outcomes. Thus, it is important to assess the extent to which forest fragments of various sizes are expected to host and sustain the original bird communities. A common approach to achieve this assessment is to examine whether species assemblages across fragments are nested or if species occur in a random fashion. In a nested pattern, smaller assemblages are nested subsets of increasingly bigger ones, which causes small fragments to exhibit both predictable and very similar species composition [12-14]. In contrast, a random species distribution leads to dissimilar species composition, creating some levels of 
complementarity of species lists among small fragments. These two patterns are linked to the SLOSS debate (single large reserves vs. several small reserves) and evoke different conservation strategies [15].

The second reason to examine forest bird community responses at this large geographic scale is to gain insight into the potential factors driving species richness and composition across fragments, particularly given the characteristics of the Malagasy avifauna. Overall, variation in species richness and composition can result not only from ecological factors (e.g. area reduction per se, increased isolation, altered habitat quality and reduced habitat diversity, disruption of ecological interactions; see [16, 17]), but also the effects of passive sampling (also called sampling effects) [18]. Sampling effects refer to the failure of forest fragments to contain ("sample") certain species from the regional pool at the time that a previously continuous forest becomes fragmented. Whereas the severity of ecological impacts generally depends on fragment sizes and their degree of isolation, sampling effects are a function of the species range and the degree of patchiness of their distribution in the region. A patchy species distribution may result from external factors, such as patchiness of suitable habitats and competitive exclusion, or some intrinsic characteristic(s) of the species, including degree of rarity (see [19]). Although most studies focus on ecological factors, several characteristics of the Malagasy avifauna suggest that sampling effects are important to consider too. For example, the Malagasy avifauna is species poor ( 299 species) when compared to continental avifaunas of comparable area (e.g. Kenya: 1124 species; Botswana: 588 species; Somalia: $~ 670$ species [20]), or to other islands of similar size ranges (Borneo: $~ 420$ species; New Guinea: 600 species; [2, 7]). In addition, surveys in lowland eastern rainforest indicate that some species exhibit patchy or restricted distributions [4, 21]. Finally, many endemic forest species are naturally rare [2]. These characteristics could produce unique patterns of species and community responses to habitat loss and fragmentation at a given scale.

In this study, we used published lists of exclusively forest bird species from Andriamasimanana et al. [10], collected information on several species traits from the literature, and analyzed both datasets to 1 ) identify species that are vulnerable to habitat fragmentation and loss and determine species characteristics that may cause their vulnerability; 2) document patterns of relationships between area and distance vs. forest species richness and composition, and infer potential contributions of ecological and sampling effects in creating these patterns; and 3) examine if a pattern of nestedness exists across the species assemblages and test for an association with two fragment characteristics: size and isolation. This information is necessary to help address questions that have important conservation implications, such as the identity of species groups or ecological guilds that may need special attention, the size range of forest fragments that should be preserved to supplement existing protected areas, and the importance of different fragment parameters (e.g. size, distance from a continuous forest area, habitat quality) for maximizing conservation efforts.

\section{MATERIALS AND METHODOLOGY}

\section{Eastern Lowland Rainforest Avifauna}

Of 179 bird species found in this ecosystem, 90 are forest species, 89 are endemic, 45 are restricted to the eastern rainforest and at least 9 are restricted to the lowland rainforest $[3,4]$. Species richness does not appear to exhibit significant latitudinal variation [4], but uneven elevational species distributions of endemic species have been reported. Specifically, low-elevation rainforest $(<800 \mathrm{~m})$ hosts fewer species when compared to mid-elevation rainforest $(800-1,800 \mathrm{~m})$ [3, 22], even though both have equivalent area [23]. Species richness is generally constant for the lowland rainforest $(<$ $800 \mathrm{~m}$ ), but it significantly declines above $1300 \mathrm{~m}$ [4]. While elevational generalists are mainly canopy feeders, lowland specialists are mostly insectivores that utilize sub-canopy substrates (ground, understory, bark), which denotes a high degree of ecological specialization [3]. Many rainforest bird endemic species $(n=23)$ are threatened [4, 24], but most species in the highest category of threat (i.e. critically endangered) are limited to lowland eastern rainforest (e.g. see [25, 26]). These characteristics highlight the urgent need to assess the responses of the eastern lowland rainforest avifauna to habitat loss and fragmentation.

\section{Site Characteristics, Species Lists, and Additional Data Collection}

Andriamasimanana et al. [10] used three reference sites $(10,000-73,000 \mathrm{ha})$ and seven fragments of increasing size (510-6,680 ha) and distance (isolation) from each other (0.45-20 km), all below $800 \mathrm{~m}$ elevation except for one reference site (see Appendix A). Species lists were obtained from direct field surveys for six fragments, and from the literature for one fragment and the reference sites $[10,27-$ 29]. In the present study, we used all 10 sites examined in Andriamasimanana et al. [10] based on the characteristics of these sites and the associated species lists. The three reference sites (Zahamena National Park, Zah; Réserve Spéciale de Sandranantitra, San; Mantadia National Park, Man) remain part of a continuous and very large forest corridor (> $300,000 \mathrm{ha}$ ) and encompass the elevational and latitudinal ranges of all the fragments (Fig. 1; Appendix A). Although one reference site (Man, $895 \mathrm{~m}$ ) is at an elevation slightly above what is termed low-elevation rainforest $(<800 \mathrm{~m})$, our analyses indicate that this site exhibits a species composition similar to those of the other two reference sites and belongs to the same biogeographic zone (see Ordination, Results). For fragments, three size classes are represented (large: 6,000 ha, medium-sized: 2,000 ha; small: 600 ha) with at least two fragments in each size class. This helps detect variation in species number and composition that is potentially due to factors other than size and distance. For example, there is some evidence for selective logging in all fragments except one (And, Appendix A) [27].

We believe these species lists can be used for a first assessment of bird responses to forest fragmentation for several reasons. First, species lists were collected during the major breeding season of the year using similar survey techniques. Specifically, all seven fragments were surveyed 
between November and December with six of them visited by the same team of investigators (i.e. all but And; Appendix A; Fig 1) [10, 27, 28]. For reference sites, species lists for two sites were collected in September (Zah) and November (Man) and for one site in January (San) [27, 28]. For all sites, bird surveys were conducted early in the morning (4:30 to $10: 30 \mathrm{am}$ ) and late in the afternoon (after 4:30 pm) using the MacKinnon lists technique (ten species lists with ten species recorded per list) [30, 31], which overcomes bias associated with observers' expertise as well as the effects of environmental conditions on species detectability [32]. Different numbers of sampling localities were visited across sites based on their sizes to ensure that all occurring species were detected; each sampling locality was visited for four to five days. Species lists were augmented using the presence of nests, feathers, and pellets as well as playbacks of vocalizations to help detect rare species [27]. Second, species lists of at least two fragments were available for each of the three fragment size classes we examined, which can be used to overcome potential artifacts by examining patterns both within and between size classes to infer the main trends. These two aspects are important because our analyses mostly focus on bird communities across fragments (e.g. vulnerable species, species-area relationship, pattern of nestedness; see Data Analyses). Finally, given the wide geographic spread of the reference sites (Fig. 1), the corresponding species lists are likely to provide an adequate representation of the original bird species pool in the region prior to forest fragmentation (Fig. 1). This helps assess the potential role of both pas- sive sampling (sampling effects) and ecological factors on species' absence across fragments.

We also collected non-forest species numbers for each site from the literature. Lists of forest and non-forest species were obtained during the same studies but they were published separately (see Appendix A for all sources). We mainly focused on forest birds and only analyzed non-forest bird species for comparison. In addition, several species' characteristics and IUCN threat status were collected from various sources [2, 4, 24, 33]. Species characteristics include: 1) geographic distribution (e.g. northeast, southeast), 2) elevational range (e.g. low-elevation, elevation generalist), 3) natural abundance (e.g. rare, common), 4) body size (e.g. small, large, very large), 5) habitat use (e.g. terrestrial, arboreal), 6) habitat type (e.g. undisturbed rainforest, secondary growth, deciduous dry forest, mangrove), and 7) diet (e.g. insectivore, frugivore).

Forest species lists for the fragments and reference sites along with non-forest species numbers across sites are presented in Appendix A. Data on species' characteristics and IUCN threat status are compiled in Appendix B.

\section{Data Analysis}

\section{Patterns of Species Loss and Vulnerable Species and Guilds}

We characterized patterns of species loss and identified vulnerable species and guilds using three approaches. First,

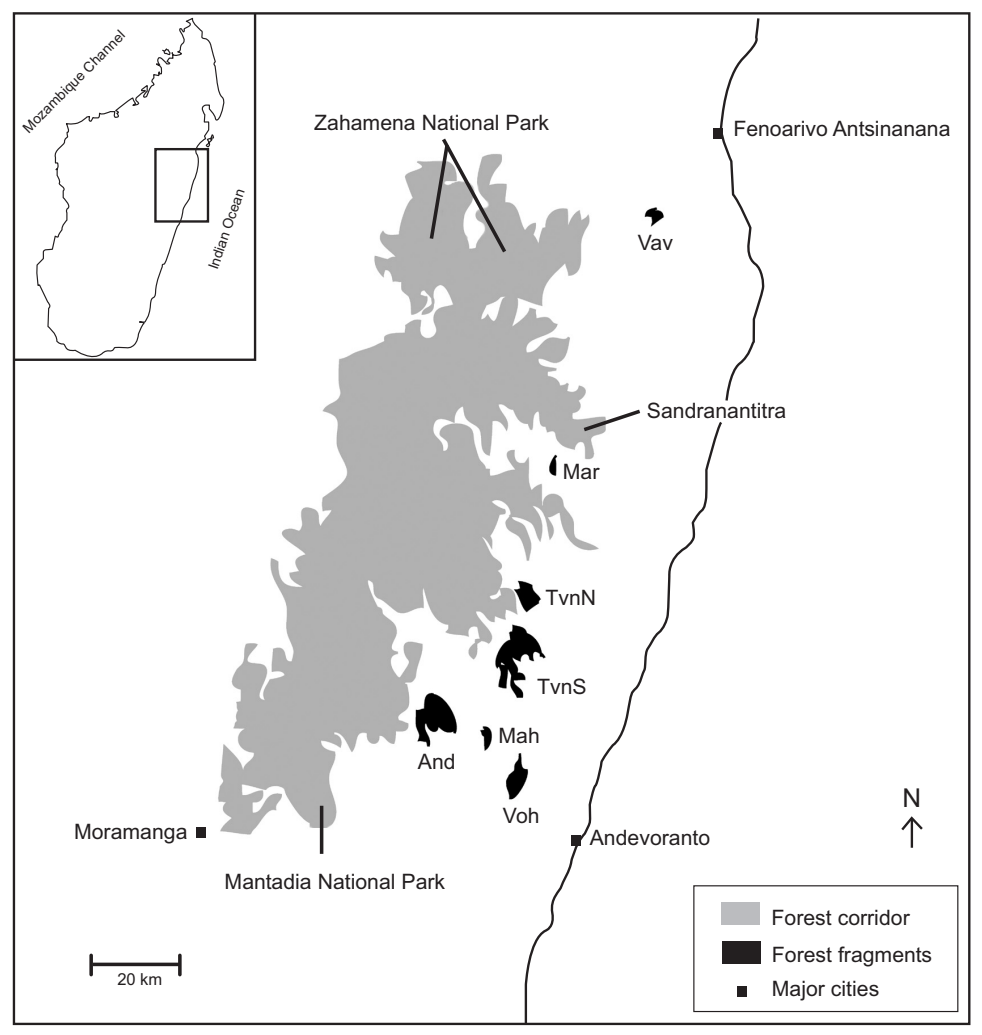

Fig. (1). Map of the Mantadia-Zahamena corridor showing the three reference sites and the seven forest fragments examined in this study (modified from International Resources Group Ltd. [27]). The following name abbreviations were used for forest fragments: TvnS = Tantavona (Anjiro Sud, Ambalarondra), And = Andriantantely (Brickaville), TvnN = Tantavona (Anjiro Nord, Ambalarondra), Voh = Vohitralanana (Brickaville), Vav = Vavazahana (Vavatenina), Mar = Marokitay (Ambodilazana), Mah = Mahalaza Razanaka (Brickaville). 
we defined different species groups based on species' characteristics (e.g. by ecological guild; see Appendix B) and compared the magnitude of loss among different groups across the three fragment size classes using the species list of the Zahamena National Park as our reference. Because the Zahamena National Park is the largest site in this study and also exhibits the highest species richness among the reference sites (Appendix A), this site can help assess species loss due to both ecological factors and sampling effects across fragments. Second, we assessed species vulnerability by computing species' frequencies of occurrence using a scale of 1 to $10(n=10$ sites $)$ and recording sites where species of a given frequency occurred (e.g. reference sites vs. large, medium-sized or small fragments). Finally, we identified species characteristics that were potentially associated with species vulnerability by documenting the following traits: geographic distribution, elevational range, natural abundance, body size, habitat types, habitat use, and diet (see Appendix B for detailed information on species groups and ecological guilds). For natural abundance, geographic range and habitat specificity of rare species were additionally examined, as these are two dimensions of rarity identified by Rabinowitz et al. [34].

\section{Potential Factors of Species Loss}

We investigated relationships between area and distance vs. species richness and species composition (i.e. species identity, species groups or guilds) using ordination and regression models. Because our sample size ( $\mathrm{n}=7$ fragments) prevented us from using a multivariate statistical framework with complex models (e.g. multiple regression models with interaction effects), we relied on exploratory and univariate methods to gain insights into these relationships. For species composition, we performed a bird community ordination based on the Bray-Curtis distance measure [35] using the Nonmetric Multidimensional Scaling (NMDS) [36] in the R package "vegan" [37], after first standardizing the data by sample size. Fragment size and distance were then plotted to visualize potential relationships with the degrees of similarity among bird communities across sites. For species richness, we first evaluated the spatial independence of the data based on Moran's I [38] and conducted a preliminary assessment of species-area and species-distance relationships using correlation tests. Simple regression lines were graphed for visual assessment and potentially influential data points were identified by computing Cook's $D$ [39]. These analyses were repeated on non-forest species for comparison purposes. Second, we examined relationships between area size and distance vs. forest species richness under a regression framework using the generalized linear models. We constructed separate (i.e. univariate) models with log link function and Poisson distribution to relate area size and distance to species richness using the PROC GENMOD of SAS [40]. Whenever overdispersion was suspected (e.g. deviance/degree of freedom $>1$ ), which can lead to incorrect conclusions, we modeled species richness using a negative binomial distribution for comparison. If both size and distance effects are statistically significant, we measured model fit and identified the predictor variable that best fit the data based on an information theoretic approach (Akaike Information Criteria; AIC). Finally, after area was found to be a strong predictor of species richness (see Results), we inves- tigated potential effects of this variable on the proportions of species from different groups and ecological guilds across the fragments. We examined these relationships using correlation tests and generalized linear models with logit link function and binomial distribution. For all analyses, the level of significance of 0.05 was adopted, except for multiple testing for which the False Discovery Rate (FDR) controlling procedure was applied [41]. Unlike traditional methods which seek to control familywise error rate (type I error; e.g. Bonferroni correction), FDR does not aim to reduce the threshold of $\alpha$ significance, but focuses on the expected proportion of false positives among all significant results at the $\alpha$ level (i.e. no increased type II error) [42].

\section{Nestedness and Potential Determinants}

We assessed nestedness of species assemblages across fragments and examined the potential association with two site characteristics: size and distance. Three popular measures of nestedness were used: 1) the modified matrix temperature metric $\mathrm{T}[13,43,44]$, which emphasizes the patterns of species' absence and presence in predominantly filled and less filled portions of the incidence matrix [45]; 2) the discrepancy measure BR [46] in the modification of Ulrich and Gotelli $[43,44]$, which focuses on the number of presences (1's) and absences (0's) that prevent the incidence matrix from exhibiting a perfectly nested pattern; and finally, 3) the recently developed metric, NODF (Nestedness measure based on Overlap and Decreasing Fill; [47]).

We assessed nestedness and its determinants in two ways. First, we ordered columns and rows in the incidence matrix according to their marginal totals and assessed whether pattern of nestedness existed in the dataset using $\mathrm{T}$, BR and NODF. Second, we used gradient analyses, which consist of ordering the incidence matrix according to the site characteristic(s) of interests (e.g. area, distance) and comparing the degree of nestedness to identify the most dominant driver [48]. Computation of the three metrics was carried out using NODF-Program version 1.1 [49]. Probability values were obtained based on 10,000 randomly assembled communities under the fixed row-fixed column constraint model and with 100,000 swaps. To verify potential artifacts associated with the origin of fragment species lists, we conducted the analyses first on all fragments, and then repeated them without And (see Appendix A).

\section{RESULTS}

A total of 38 forest bird species were recorded across sites excluding non-forest and high elevation species. Thirty six species were found in the largest reference site, Zahamena National Park. Eleven species were recorded only in the three reference sites. About half of the species found in Zahamena National Park (the largest reference site) were absent in large fragments (> 4,000 ha). Up to two thirds of the Zahamena species were missing in fragments of medium size ( 2,000 ha). At $~ 600$ ha, over $80 \%$ of the species were absent (Appendix A).

\section{Patterns of Loss Across Fragment Size Classes}

Patterns of losses among guilds and other species groups differed as fragment size decreased (Fig. 2). Two contrasting 


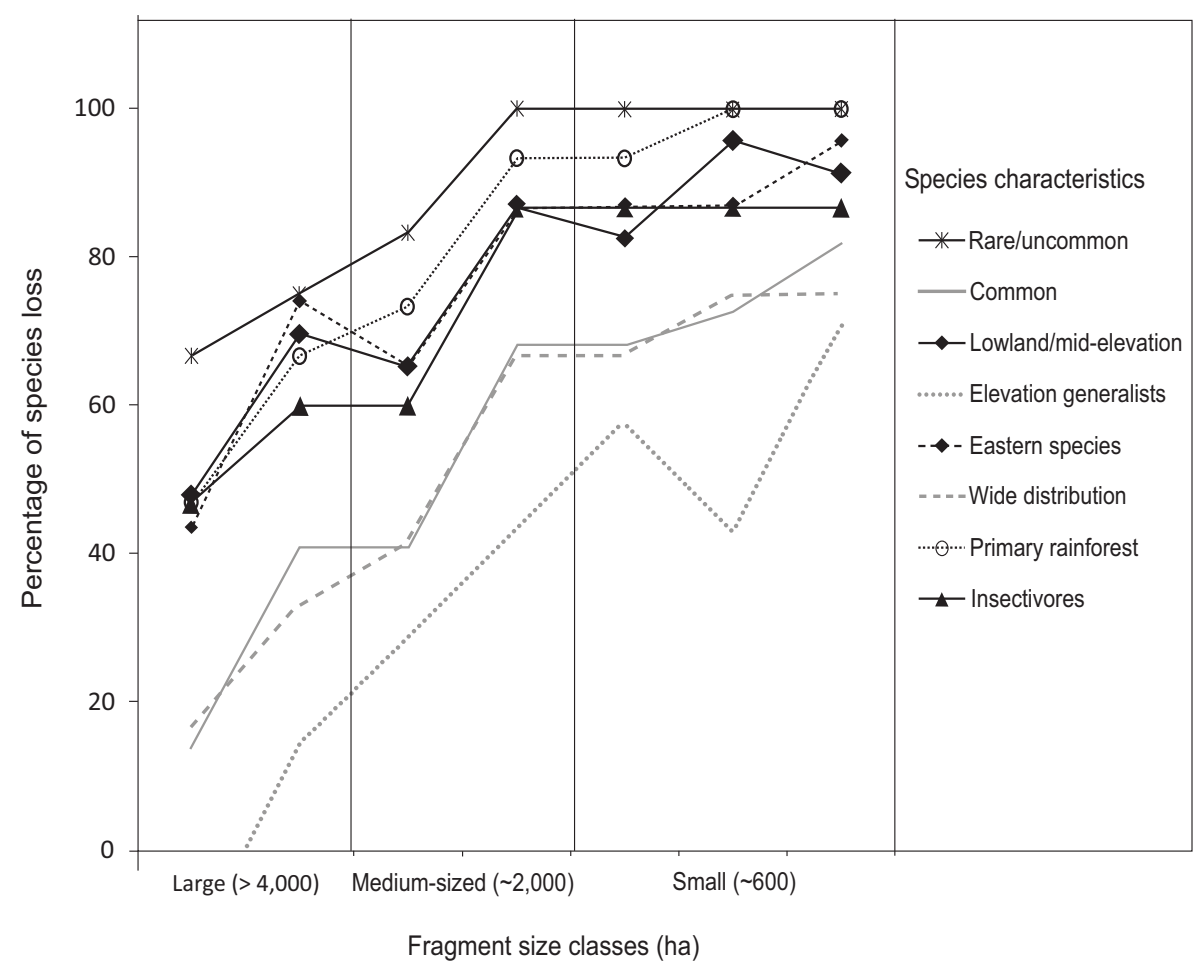

Fig. (2). Patterns of forest species loss per group across the three fragment size classes (x-axis not scaled). Black curves with markers correspond to rare and uncommon species and species that exhibit some degree of ecological constraints (e.g. diet and restricted distribution). Grey and unmarked curves represent common, widespread and generalist species. Percentage of species loss was based on the forest species list of the Zahamena National Park (Zah), the largest reference site (Appendix A, Fig. 1).

patterns were identified, indicating different responses of rare species or species with some degree of ecological constraints vs. common and generalist species. Specifically, 50$70 \%$ of rare and uncommon species, lowland and midelevation species, insectivores, species restricted to primary rainforest, and eastern species on the Zahamena species list were absent in large fragments (> 4,000 ha). Species loss can reach $90-100 \%$ in fragments of medium size ( $\sim 2,000$ ha), and remain consistently high in small fragments ( $600 \mathrm{ha})$. This pattern is in contrast to common species, elevational generalists, and widely distributed species (beyond the eastern rainforest) for which $<30 \%$ were absent in large fragments and $<70 \%$ were absent in fragments of medium size and in some small fragments (Fig. 2). To investigate patterns of species loss in greater detail, we subsequently examined vulnerable species across sites and documented their characteristics.

\section{Characteristics of Vulnerable Species}

Species lists and frequency of occurrence across the reference sites and fragments are shown in Appendix A. Species occurrences are highlighted in grey, which reveals a strong tendency of species with low frequencies (i.e. $\leq 3)$ to occur only in reference sites. As species frequency increases, species are also seen to occur in increasingly smaller fragments. Finally, of the 38 study species, eighteen shared the same frequencies with at least another species and also occurred in the exact same set of sites as them (Appendix A), which is further evidence of the relationship between species frequencies and species' patterns of distribution across sites.
Based on these findings, we considered species' frequencies of occurrence as an approximate measure of species' degree of vulnerability to habitat fragmentation and loss in this study. In other words, the lower the species frequency the more likely the species is to be vulnerable. We describe four species groups based on species' frequency of occurrence in conjunction with the minimum fragment size class where species were seen to occur.

The first group includes ten species characterized by a frequency of 0.1 and 0.2 . These species are found in reference sites, but absent across fragments, with one exception (Aviceda madagascariensis). Most species are rare or uncommon, restricted to undisturbed rainforest at low elevation, and a few with a patchy distribution. More than half of these species have large or very large body size (mostly raptors). Species of small body size are insectivores. Nearly all species have an IUCN threatened status [24].

The second group is composed of eleven species characterized by a frequency of 0.3 and 0.4 . They also occur in large fragments (> 4,000 ha) except for two (Neodrepanis coruscans and Pseudobias wardi) restricted to reference sites. Most are restricted to the eastern region and occur in undisturbed rainforest and secondary growth, at low and mid elevation. Half of these species are rare or uncommon and the other half are fairly common. Five species either chiefly feed on insects or exhibit a strictly insectivorous diet. Half of the species are classified as vulnerable or near-threatened by the IUCN [24]. 
The third group has eight species characterized by a frequency of 0.5 and 0.6. They also occur in fragments of medium size (> 2,000 ha) (except Philepitta castanea), but not in small ones. Most are common species with large distributions (beyond the eastern portion of the island). These species occur in various forest habitats, including undisturbed rainforest, deciduous forest, and secondary growth. Only one species has an IUCN threatened status [24].

The last group includes nine species all with a frequency above 0.6. These species occur even in small fragments (> $500 \mathrm{ha}$ ). They are common or fairly common and with large distributions (half are found throughout the island). Most are terrestrial and of large body size and a few are insectivores. These species are more or less generalist species with respect to habitat types and especially elevation. One species is classified as near-threatened by the IUCN [24].

Based on these species characteristics vulnerability appeared to be associated with one or a combination of any of the following main traits: natural rarity; a large body size coupled with a high trophic level (i.e. raptors) and ecological specialization, namely insectivorous diet and habitat restriction.

To identify other characteristics of rare species that may be associated with their apparent vulnerability in this study, we examined two dimensions of rarity identified by Rabinowitz et al. [34]: geographic range and habitat specificity. Overall, the seven rare species we examined exhibited different characteristics and can be placed in three separate groups. First, one species (Geobiastes squamigerus) exhibited only one rarity dimension. This species has a very narrow distribution (northeast) but with apparently less stringent habitat requirements. For example, the species has been seen in secondary growth [2] or habitats with a certain degree of disturbance [50]. It is also thought to be locally common but regionally rare and probably exhibits a patchy distribution [50]. The species was found in reference sites and one large fragment ( 4,000 ha). On the other hand, four species (Brachypteracias leptosomus, Mesitornis unicolor, Eutriorchis astur, Oriolia bernieri) displayed both (or nearly both) dimensions of rarity. They are all restricted to the eastern primary rainforest and show an affinity for undisturbed habitats, with two species exhibiting an even narrower distribution (northeast) and a more restricted habitat range (lowland rainforest) (i.e. Eutriorchis astur, Oriolia bernieri). All but Brachypteracias leptosomus were found only in the reference sites. The final group contains two raptors (Accipiter madagascariensis, $A$. henstii) which do not show any of the two dimensions of rarity investigated. Raptors often exhibit naturally small population size and a low density and require large areas to maintain viable populations due to their large territories.

As for insectivores, the most vulnerable (i.e. frequency $\leq$ 3) species are a large-bodied terrestrial species (Mesitornis unicolor), a strictly terrestrial species (Mystacornis crossleyi), a ground and low understory species (Bernieria tenebrosus), and seven mid and upper stratum species (Neodrepanis coruscans, Pseudobias wardi, Newtonia fanovanae, Tylas eduardi, Hypositta corralirostris, Neomixis viridis, Newtonia amphicroa).

\section{Potential Factors of Species Loss: Area and Distance Ef- fects}

Results from the NMDS ordination of bird communities across sites are shown in Fig. (3). A stress of 0.01 was

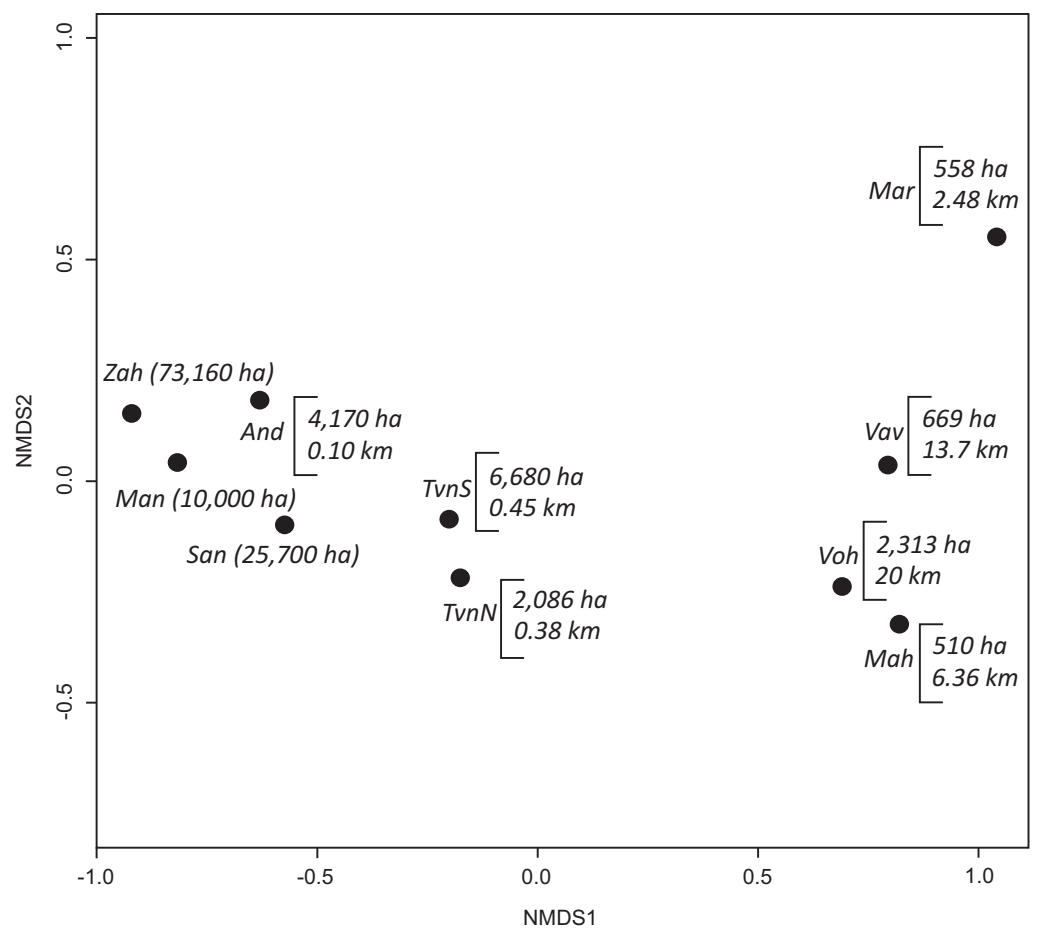

Fig. (3). NMDS (non-metric multidimensional scaling) ordination plot of bird communities (represented by small circles) across sites (see text and Fig. (1) for name abbreviations for sites) based on Bray-Curtis similarities and with area size and distance from the MantadiaZahamena corridor plotted. 
achieved with two axes, and a clear positive linear relationship was obtained between the observed dissimilarity and the ordination distances (for linear fit, $r^{2}=0.99$ ). Both indicate that very little information was lost using two axes and the addition of a third dimension is not necessary to explain species composition [36]. The NMDS plot revealed patterns that are consistent with fragment size. For example, small fragments are all placed in the right hand portion of the plot, forming a set. Large and medium-sized fragments are placed in the middle of the plot, whereas reference sites are located in the left-hand side. Thus, small fragments and reference sites are farthest apart on the graph as expected based on their size (Fig. 3). One exception to this general pattern was observed for a medium-sized fragment, Voh (2,313 ha), which was placed near small fragments. Another striking pattern was the clustering of one large fragment, And (4,170 ha), with the reference sites, suggesting similar species compositions between them. For distance, there appears to be some patterns of association with species composition, but these patterns are not as clear and consistent as those observed for fragment size.

No evidence of spatial autocorrelation was detected in the dataset $(P=0.81$ for Moran's $I)$. No significant correlation was detected between size and distance $(r=-0.38, P=$ 0.39 ). For species-area and distance-area relationships, forest species richness was significantly correlated with log (area) ( $r=0.80, P=0.02$; Fig. 4), but not with distance from the corridor ( $r=-0.59, P=0.16$ ) (Fig. 4). A single potentially influential data point was identified for size (TvnS; 6,680 ha; Cook's $D=3.75)$. For non-forest species, all correlation tests were non-significant $(P>0.05)$ (Fig. 4).

When the effect of each physical variable was examined under the generalized linear model specified, size was statistically significant whether the outlier was removed $(P<$ 0.0001; AIC $=32.69)$ or not $(P=0.02$; AIC $=45.02)$. On the other hand, a low but non-significant $P$-value was obtained for distance $(P=0.06$; AIC $=46.87)$. Based on the overall results, we considered fragment size as the strongest predictor of forest species richness and assessed its relationship with the proportions of different species groups and ecological guilds across fragments.

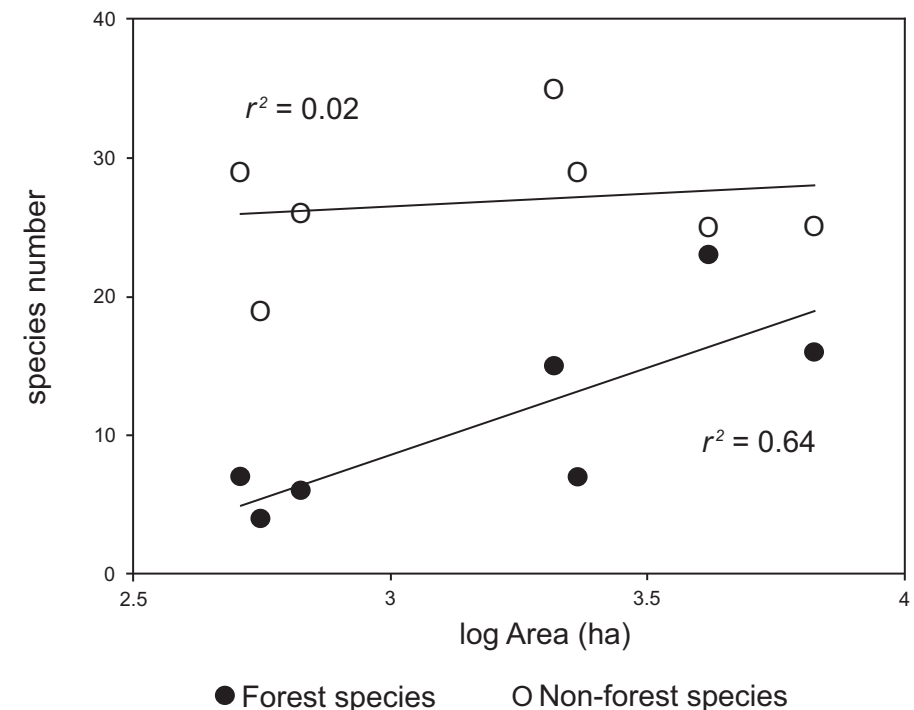

Common species $(r=-0.83, P=0.03)$ and species restricted to undisturbed rainforests $(r=0.85, P=0.03)$ were found to exhibit significant correlation with log (area) after the false discovery rate controlling procedure was applied. Specifically, the smaller the fragment size, the smaller the proportion of primary forest species observed and the higher the proportion of common species. In contrast, none of the groups and ecological guilds examined were significantly associated with size based on the linear generalized models specified, although low $P$-values were obtained for species restricted to undisturbed rainforest and for common species $(P=0.07)$.

\section{Nestedness and Determinants}

Results of the nestedness analyses are presented in Table 1. Two metrics, $T$ and $B R$, were not significant throughout the analyses, indicating the absence of a pattern of nestedness. In contrast, all observed NODF were significantly smaller than the mean NODF expected by chance, although $P$ values bordered on the level of significance $(0.01<$ $P \leq 0.05)$. These NODF and $P$ values not only point to the absence of nested patterns, but they also suggest a potential presence of other non-random patterns in the dataset (see Discussion). Nevertheless, the observed NODF were always within the confidence limits obtained from the null models.

\section{DISCUSSION}

In this study, we examined 1) characteristics of vulnerable forest bird species related to decreased fragment size and increased fragment isolation; 2) patterns of relationships between fragment size and distance with species richness and composition, and the underlying driving factors; and 3) characteristics of the resulting species assemblages across three fragment size classes in the Malagasy lowland rainforest. Detailed discussion of those aspects follows.

\section{Patterns of Species Loss and Vulnerable Species}

Patterns of loss across different forest species groups reveal that they respond differently to habitat fragmentation

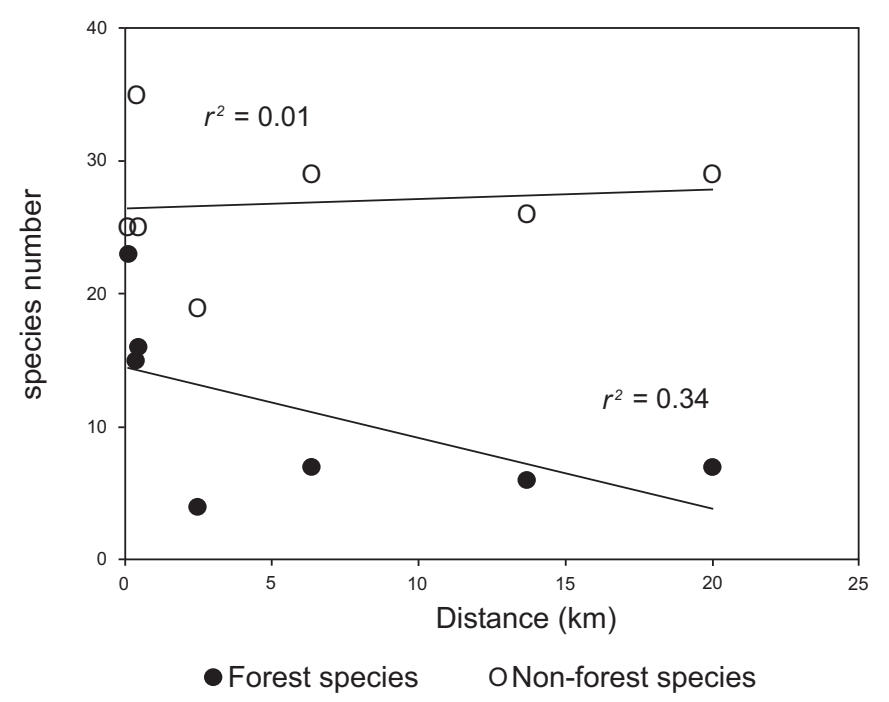

Fig. (4). Species-area and distance-area relationships for forest and non-forest species across the seven study fragments ( $600-\sim 6,000$ ha). 
Table 1. Nestedness Analyses Using Three Metrics Under Different Sorting Criteria

\begin{tabular}{|c|c|c|c|c|}
\hline Sorting Criteria & Metrics & Observed & Mean (95\% CI) & P Value \\
\hline \hline & T & 5.41 & $10.92(9-13)$ & 0.26 \\
\hline Richness & BR & $10.32-9.64)$ & 0.36 \\
\hline & NODF & 71.67 & $15.93(71.31-75.61)$ & $0.04 *$ \\
\hline Area & T $12.03-17.15)$ & $12.23(10-15)$ & 0.39 \\
\hline & BR & 14.99 & $73.08(70.52-74.62)$ & 0.09 \\
\hline Distance & NODF & 70.84 & $51.99(50.18-53.73)$ & 0.23 \\
\hline & BR & 51.33 & $12.23(10-15)$ & 0.09 \\
\hline
\end{tabular}

$\mathrm{T}$ = modified matrix temperature metric [13, 43, 44], BR = discrepancy measure [43, 44, 46], NODF = Nestedness measure based on Overlap and Decreasing Fill [47]; Mean = mean metric values obtained from the simulated random communities; $\mathrm{CI}=$ confidence intervals based on 10,000 random communities; * below the level of significance specified $(\alpha=0.05)$.

and loss within our fragment size ranges $(\sim 600-\sim 6,000$ ha). Two potentially correlated species traits appear to be involved: degree of rarity and ecological specialization (e.g. diet and habitat restriction). Rarity is a good predictor of species' vulnerability to extinction [51], but the examination of the underlying life history and ecological traits can provide further insight to inform conservation practices [34]. The seven rare species we investigated exhibited different characteristics, which suggest that they are likely to be sensitive to different factors. Thus, while degree of rarity may provide a first indication of the potential vulnerability of a species, it may not reliably predict their vulnerability under different circumstances (e.g. location of the forest fragments, habitat quality, or other factors associated with species intrinsic characteristics).

In general, ecological specialists are expected to be vulnerable due to their adaptation to a very specific set of ecological conditions. Thus, the vulnerability of species with known habitat restrictions is not surprising. On the other hand, the apparent vulnerability of some insectivores is puzzling. Insectivores have shown vulnerability to habitat fragmentation and loss elsewhere [7, 52-54] and several ecological hypotheses have been proposed, including food scarcity [55], microclimate [56, 57], and habitat specificity [57, 58]. Their applicability to this study is, however, unclear because insectivores were lost from our fragments $(<4,000 \mathrm{ha})$ which were much larger than those used in these other studies. Another potential reason for this pattern is human disturbance greatly altering habitat quality across sites due to selective logging in fragments [27]. Degree of rarity may be involved as well given that our most vulnerable insectivores are all rare, fairly common or uncommon (frequency $\leq 0.3$; Appendices $\mathbf{A}, \mathbf{B}$ ), whereas our less sensitive and non-sensitive insectivores (frequency $\geq 5$; Appendices A, $\mathbf{B}$ ) are common. Regardless of the causes of these patterns, it is worth noting that many of our vulnerable insectivores were also reported as area sensitive, vulnerable, or locally extinct in two other studies conducted on much smaller fragments in the High Plateau and the eastern littoral forests [7, 9]. Further research is a priority given that most endemic insectivores are lowland specialists [3].

\section{Potential Factors of Species Loss}

We used various statistical methods to infer factors that shape bird community characteristics across our fragments. Ordination, correlation and regression analyses showed that, although distance from the Mantadia-Zahamena corridor remains a potentially important factor, fragment size is the strongest predictor of forest bird species richness and also influences species composition. The predictive power of fragment size documented herein may result not only from some underlying ecological factors but also from the inherent spatial and biological sampling processes associated with habitat loss, which we referred to as sampling effects (see Introduction; [16-18, 59, 60]). In this study, the original species pool in each fragment is not known, so the relative contributions of ecological vs. sampling effects cannot be quantified. Nevertheless, the following lines of evidence suggest that both factors are likely to be involved.

The role of ecological factors is consistent with the progressive disappearance of species restricted to the undisturbed eastern rainforest, the prevalence of more generalist forest species in small fragments and the discrepancy between the responses of forest vs. non-forest species to area reduction (Fig. 4; Appendix B). The absence of statistically significant linear relationships between certain ecological guilds vs. area size does not necessarily imply that area reduction has no effect on these species. These findings may partially result from a lack of power in our analyses $(n=7$ fragments) or inconsistent species responses as fragment size decreases. For example, many insectivores were lost abruptly below 4,000 ha (Appendices A, B). Because most insectivores are also arboreal and of small body size, the abrupt disappearance of insectivores probably explains the absence of significant linear relationships between fragment size vs. body size and habitat use. 
In addition to area reduction, habitat quality may also be further altered by selective logging in these fragments [27], which can greatly disrupt microhabitats due to the removal of trees and the associated disturbance involving drag trails and other vegetation removal (e.g. lightweight trees for rafts, lianas to drag trees) [61-63]. In this respect, one interesting finding is the clustering of And (4,170 ha) with reference sites in the ordination plot (Fig. 3), whereas TvnS (6,680 ha) was placed farther apart. Among the fragments we examined, And is the only one visited by a different team of investigators, which might suggest an artifact of field data collection. However, all sites were visited by experienced investigators using the same survey technique. Another potentially contributing factor is the distance of And $(0.10 \mathrm{~km})$ from the corridor, although distance effect alone may not explain this pattern given that another fragment, TvnS $(0.45 \mathrm{~km})$, was also located near the corridor. A more likely explanation is the potential effects of selective logging on local bird communities. Specifically, And has an almost intact forest, whereas TvnS is heavily perturbed by selective logging [27]. TvnS was identified as an outlier in our correlation and regression analyses.

The proposed contribution of sampling effects is based on the evidence for restricted and/or potentially patchy species distributions (including certain characteristics of our vulnerable rare species), the difference in species richness of fragments of the same size class (e.g. Voh vs. $T v n N$ ), and the finding that rare and extremely rare species were restricted to reference sites but did not consistently occur in all of these sites. Another relevant finding is the negative correlation between area size and proportion of common species, which can be explained by the progressive increase in the proportions of uncommon and rare species in the species pool as fragment size increases. This pattern can result, at least partially, from sampling effects.

\section{Pattern of Nestedness}

Analyses of nestedness can be informative regarding the patterns of community disassembly in response to forest fragmentation [64]. Nested patterns can occur when fragment size decreases and/or fragments become increasingly isolated, causing selective and predictable species loss that, in turn, creates redundant species composition in small fragments. Thus, the presence or absence of such a pattern across the study communities can inform conservation strategies, such as those associated with the SLOSS debate [15]. In this study, no evidence of nested patterns of forest bird species assemblages were found across individual fragments, which is in contrast to findings elsewhere for a variety of animal and plant communities found in human-induced or naturally fragmented landscapes [64-67]. However, we should note that a degree of nestedness is indeed apparent in the dataset if we compare fragments from different size classes (i.e. large vs. medium-sized vs. small) (see Appendix A). Three factors may have contributed to the absence of nested subset pattern at the individual fragment level. First, the similarity in the sizes of many of the fragments we compared probably made it less likely that a clear nested subset pattern arose among them. In addition, as discussed earlier, no single factor seemed to represent a dominant driver of species loss across fragments, so species loss may not have been selec- tive and consistent throughout to form nested assemblages at this geographic scale. Our fragments are certainly significantly larger than those used in classical studies of forest fragmentation on birds in which strong deterministic processes appeared to operate ( $<100$ ha; [52, 54, 68]). Finally, species assemblages may not have reached equilibrium yet. Unfortunately, the exact timing when these fragments were created is unknown to assess this possibility.

A departure from nestedness can be evidence of either a random distributional pattern or other non-random patterns (e.g. non-inclusive sets, checkerboard, high turnover) that arise due to other underlying biological factors, such as exclusive species interactions and high species turnover (see [69]). In this study, two measures of nestedness, $\mathrm{T}$ and $\mathrm{BR}$, clearly suggest a random species composition at the fragment level, whereas NODF indicates that species may follow other non-random distributions as inferred from the marginally significant $P$ values. Conceptually, NODF has been shown to be more consistent than the two other metrics due to its robustness to basic matrix properties [45, 47]. However, we should note that computed values of this metric still fall within $95 \%$ confidence limits. Our $P$ values for NODF were probably biased due to the shape of the null distributions from which they were computed (see Methods). This is not uncommon given that null distributions from randomly constructed matrices are rarely symmetric normals (Werner Ulrich pers. comm.).

\section{CONCLUSION}

We have identified several patterns of forest bird species responses to habitat fragmentation and loss in the Madagascar lowland rainforest as well as the potential factors and processes involved. Despite these findings, certain caveats are warranted due to the characteristics of our datasets and unknown effects of other potentially confounding factors. Specifically, species lists generally contain some level of errors associated with data collection artifacts [70], the extent of which is unknown in this study. Similarly, the exact age of the fragments is unknown although it is likely that they were formed roughly contemporaneously due to their similar elevational ranges, making them equally accessible to humans [6]. The low sample size ( $n=7$ fragments) limited our ability to thoroughly examine the various effects of fragment size and distance from the Mantadia-Zahamena corridor on species richness (e.g. patterns of interactions between the effects of the two physical variables). Finally, only a qualitative (vs. quantitative) assessment of the intensity of selective logging was available among sites.

Nonetheless, the extent to which these aspects may be relevant to our analyses was either addressed in the methodology or in the interpretation of results. Overall, these limitations are unlikely to qualitatively affect the main patterns of bird species responses documented herein. Given the absence of knowledge about the effects of forest fragmentation and loss on resident endemic birds in the lowland eastern rainforest of Madagascar, our findings will serve as important guides for future studies.

Specifically, our study suggests that deforestation is likely to result in the loss of some endemic forest bird species in the lowland rainforest of Madagascar even when the result- 
ing fragments are large, simply because of sampling effects associated with the existence of many rare species or species with restricted and/or patchy distributions. The finding that recently extinct Malagasy bird species were often rare or absent in anthropogenic fragments also supports our results (e.g. [71]). At the scale of our fragment sizes ( 600 to $~$ 6,000 ha), habitat fragmentation and loss also appear to cause predictable patterns of species loss that result in very similar species compositions across smaller fragments (nested subsets), but these patterns seem to arise only between fragments of significantly different sizes (up to three-fold size differences based on the size classes used for this study). These two findings suggest that while conservation efforts should generally prioritize the protection of large fragments, rare species require the protection (and enhancement) of fragments where they occur, even if the fragment is small. For forest bird species, degree of natural rarity and ecological specialization predict their vulnerability. Area size was significantly associated with forest species richness and composition, but area-related ecological processes and sampling effects may not be the only factors involved. Distance from the remaining continuous forest block is also a likely contributing factor. Similarly, although size is frequently used as a proxy for assessing the conservation value of a forest fragment, our study strongly suggests that for the lowland eastern rainforest birds other forms of human disturbances, particularly selective logging, are also important to consider. Another interesting finding is that an area of 4,000 ha hosted most of the regional forest bird species pool when the forest is still intact and the fragment is not too far from continuous forest. Overall, in light of the general characteristics of Malagasy avifauna (relatively species poor avifauna, patchy and restricted species distributions, tendency of endemic species to be rare), future studies should examine in detail the interplay between sampling vs. ecological fac- tors across fragments of various size ranges in the lowland eastern rainforest, particularly in the context of other threats (e.g. selective logging). Given the current human population growth rate on the island (averaging $2.7 \%$, [11]), the destruction of this ecosystem will likely continue, leading to the increasing reliance on forest fragments to augment conservation efforts. Thus, these aspects are important to document at this large geographical scale to help determine the size range of forest fragments that should be preserved to supplement existing protected areas.

\section{CONFLICT OF INTEREST}

The authors confirm that this article content has no conflicts of interest.

\section{ACKNOWLEDGEMENTS}

This study was supported by the Beta Lambda Chapter of the Phi Sigma Biological Honors Society and the Graduate Student Association at Illinois State University. We thank Shawn Lehman for providing comments on an early draft. We also acknowledge three anonymous reviewers for their helpful comments to improve an early version of the manuscript. We thank Christoph Schwitzer for providing us with the permission to use datasets from the journal Lemur News. We thank ASITY Madagascar for giving us the permission to use a modified version of their map. Many thanks to Voninavoko Raminoarisoa (ASITY Madagascar) and Haja Rakotomanana (Université d'Antananarivo, Madagascar) for the valuable information regarding the field surveys. J.-E.R. would especially like to thank Patricia Wright (Stony Brook University), the Institute for the Conservation of Tropical Environments and the School of Biological Sciences at Illinois State University for their assistance with certain support needed for the completion of this project.

\section{APPENDIX A}

Appendix A. Characteristics of the Study Sites and the List of Strictly Forest Species and their Frequency of Occurrence Across Sites

\begin{tabular}{|c|c|c|c|c|c|c|c|c|c|c|}
\hline \multirow{3}{*}{$\begin{array}{c}\text { Site characteristics } \\
\text { Site ID } \\
\text { Size (ha) }\end{array}$} & \multicolumn{3}{|c|}{ Reference sites } & \multicolumn{7}{|c|}{ Fragments } \\
\hline & Zah & San & Man & TvnS & And & Voh & $\operatorname{TvnN}$ & Vav & Mar & Mah \\
\hline & 73,160 & 25,700 & 10,000 & 6,680 & 4,170 & 2,313 & 2,086 & 669 & 558 & 510 \\
\hline Elevation (m) & $465-675$ & 450 & 895 & $500-630$ & 530 & $80-300$ & 257-607 & $300-586$ & $550-729$ & $60-115$ \\
\hline Distance (km)* & - & - & - & 0.45 & 0.10 & 20 & 0.38 & 13.7 & 2.48 & 6.36 \\
\hline Eutriorchis astur ${ }^{1}(0.1)$ & 1 & 0 & 0 & 0 & 0 & 0 & 0 & 0 & 0 & 0 \\
\hline Accipiter madagascariensis $^{1}(0.1)$ & 1 & 0 & 0 & 0 & 0 & 0 & 0 & 0 & 0 & 0 \\
\hline Accipiter francesi ${ }^{1}(0.1)$ & 0 & 0 & 1 & 0 & 0 & 0 & 0 & 0 & 0 & 0 \\
\hline Oriolia bernieri1 (.0.2) & 1 & 1 & 0 & 0 & 0 & 0 & 0 & 0 & 0 & 0 \\
\hline Euryceros prevostii1 (0.2) & 1 & 0 & 1 & 0 & 0 & 0 & 0 & 0 & 0 & 0 \\
\hline
\end{tabular}


Appendix A. Contd....

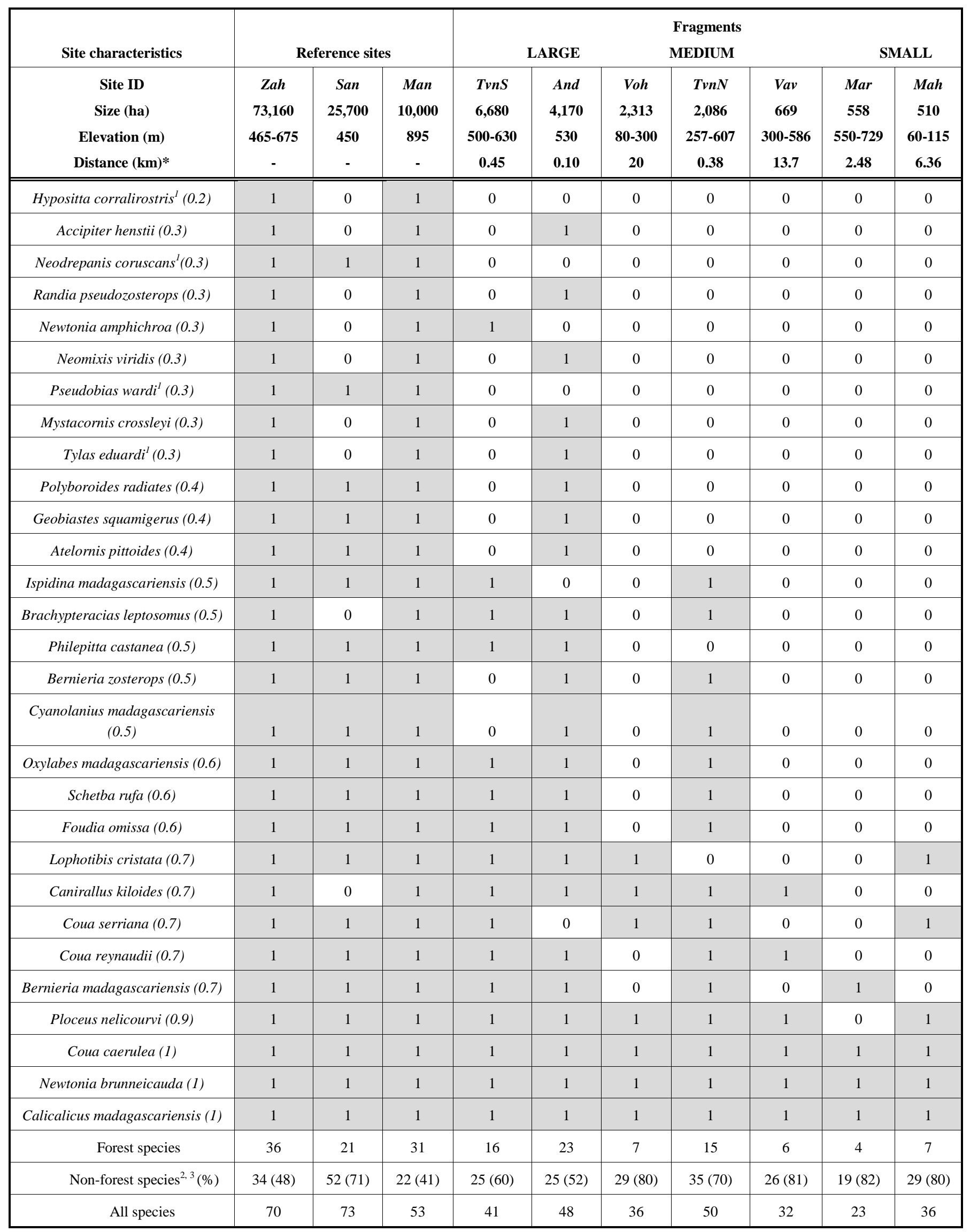


$1($ and grey cell $)=$ present, $0=$ absent; *distance from the Mantadia-Zahamena corridor (reference sites, Fig. 1); ${ }^{1}$ species only recorded in the reference sites; ${ }^{2}$ species lists are available in International Resources Group Ltd. [27]; ${ }^{3}$ percentage based on overall species richness in each site. Forest species lists of fragments and site characteristics were obtained from Andriamasimanana et al. [10], whereas non-forest species richness was available in International Resources Group Ltd. [27], and Schmid and Alonso [28]. For references sites, forest species lists and the number of non-forest species were obtained from various sources [27-29]. For all sites, the list and number of both strictly forest species and non-forest species were collected during the same survey.

Appendix B. Species Characteristics and their Frequency of Occurrence Across Sites $(n=10$ sites $)($ Compiled from [2, 4, 24, 33]).

\begin{tabular}{|c|c|c|c|c|c|c|c|c|c|}
\hline Species & $\begin{array}{c}\text { Fre- } \\
\text { quency }\end{array}$ & $\begin{array}{l}\text { Abun- } \\
\text { dance }\end{array}$ & $\begin{array}{c}\text { Elevation }^{1} \\
\left.\text { (Cat }^{2}\right)\end{array}$ & $\begin{array}{l}\text { Distribu- } \\
\text { tion }\end{array}$ & $\begin{array}{c}\text { Habitat } \\
\text { Type }\end{array}$ & $\begin{array}{c}\text { Habitat } \\
\text { Use }\end{array}$ & Body Size & Diet & $\begin{array}{l}\text { IUIC } \\
\text { Status }\end{array}$ \\
\hline $\begin{array}{c}\text { Aviceda } \\
\text { madagascariensis }\end{array}$ & 0.1 & F. com & $0-1600(\mathrm{~L}, \mathrm{M})$ & $1,2,5$ & $\mathrm{~A}, \mathrm{~B}, \mathrm{~B}^{*}, \mathrm{C}$ & Arboreal & $\begin{array}{c}\text { Very large } \\
\text { (R) }\end{array}$ & Rep, Ins & - \\
\hline Eutriorchis astur & 0.1 & Ext. rare & 0-1000 (L) & 1 (Patchy) & A & Arboreal & $\begin{array}{c}\text { Very large } \\
\text { (R) }\end{array}$ & Rep & $\begin{array}{l}\text { Crit. } \\
\text { End. }\end{array}$ \\
\hline $\begin{array}{c}\text { Accipiter } \\
\text { madagascariensis }\end{array}$ & 0.1 & Rare & 0-1500 (?) & $1,2,5,6$ & A, C & Arboreal & Large (R) & $\begin{array}{l}\text { Ins, rep, } \\
\text { birds }\end{array}$ & $\begin{array}{l}\text { Near- } \\
\text { T. }\end{array}$ \\
\hline Accipiter francesi & 0.1 & F. com & 0-2000 (L, M) & $\begin{array}{c}1,2,3,4,5 \\
6\end{array}$ & $\mathrm{~A}, \mathrm{~B}, \mathrm{~B}^{*}, \mathrm{C}$ & Arboreal & $\begin{array}{c}\text { Very large } \\
\text { (R) }\end{array}$ & $\begin{array}{l}\text { Ins, bats, } \\
\text { rep }\end{array}$ & - \\
\hline Mesitornis unicolor & 0.1 & Rare & 0-900 (L, M) & 1,2 & A & $\begin{array}{c}\text { Terres- } \\
\text { trial }\end{array}$ & Large & Ins, seeds & Vul. \\
\hline Bernieria tenebrosus & 0.1 & Rare & $?$ & $?$ & $?$ & Arboreal & Small & Ins & End. \\
\hline Newtonia fanovanae & 0.1 & Uncom & $<800(\mathrm{~L})$ & $\begin{array}{c}\text { 1, } 2 \\
\text { (Patchy) }\end{array}$ & A & Arboreal & Small & Ins & Vul. \\
\hline Oriolia bernieri & 0.2 & Rare & 0-900 (L) & 1 (Patchy) & A & Arboreal & Small & Inver & Vul. \\
\hline Euryceros prevostii & 0.2 & Uncom & 200-1800 (L) & 1 (Patchy) & A & Arboreal & Large & Ins, invert & $\begin{array}{l}\text { Near- } \\
\text { T. }\end{array}$ \\
\hline Hypositta corralirostris & 0.2 & F. com & 0-1800 (L) & 1,2 & A & Arboreal & Small & Ins & - \\
\hline Accipiter henstii & 0.3 & Rare & 0-1800 (L, M) & $1,2,6$ & $\mathrm{~A}, \mathrm{C}, \mathrm{B}^{*}, \mathrm{~B}$ & Arboreal & $\begin{array}{c}\text { Very large } \\
\text { (R) }\end{array}$ & Birds, lem & $\begin{array}{l}\text { Near- } \\
\text { T. }\end{array}$ \\
\hline Neodrepanis coruscans & 0.3 & F. com & $0-1700(\mathrm{M})$ & 1,2 & $\mathrm{~A}, \mathrm{~B}^{*}$ & Arboreal & Small & Ins, spider & - \\
\hline Randia pseudozosterops & 0.3 & F. com & $\begin{array}{c}800-1500(\mathrm{~L} \\
\mathrm{M})\end{array}$ & 1,2 & A & Arboreal & Small & Unknown & $\begin{array}{l}\text { Near- } \\
\text { T. }\end{array}$ \\
\hline Newtonia amphicroa & 0.3 & Uncom & $\begin{array}{c}500-1800(\mathrm{G} \text { or } \\
\mathrm{H})\end{array}$ & 1,2 & $\mathrm{~A}, \mathrm{~B} *$ & $\begin{array}{c}\text { All } \\
\text { levels }\end{array}$ & Small & Ins & - \\
\hline Neomixis viridis & 0.3 & Uncom & $100-2050(\mathrm{G})$ & 1,2 & A & Arboreal & Small & Ins & - \\
\hline Pseudobias wardi & 0.3 & Patchy & 0-1800 (L, M) & $\begin{array}{c}1,2 \\
\text { (Patchy) }\end{array}$ & A & Arboreal & Small & Chiefly ins & $\begin{array}{l}\text { Near- } \\
\text { T. }\end{array}$ \\
\hline Mystacornis crossleyi & 0.3 & F. com & 0-1800 (L, M) & 1,2 & A & $\begin{array}{c}\text { Terres- } \\
\text { trial }\end{array}$ & Small & Ins only & - \\
\hline Tylas eduardi & 0.3 & F. com & $0-1800(\mathrm{G})$ & 1,2 & $\mathrm{~A}, \mathrm{~B}^{*}$ & Arboreal & Small & Ins & - \\
\hline Polyboroides radiates & 0.4 & F. com & 0-2000 (L, M) & $1,2,5,6$ & $\mathrm{~A}, \mathrm{~B}, \mathrm{~B}^{*}, \mathrm{C}$ & Arboreal & $\begin{array}{c}\text { Very large } \\
\text { (R) }\end{array}$ & $\begin{array}{l}\text { Ins, rep, } \\
\text { lem, }\end{array}$ & - \\
\hline Geobiastes squamigerus & 0.4 & Rare & $0-950(\mathrm{~L})$ & 1 & $\mathrm{~A}, \mathrm{~B}^{*}$ & $\begin{array}{c}\text { Terres- } \\
\text { trial }\end{array}$ & Small & Inver/vert & Vul. \\
\hline Atelornis pittoides & 0.4 & Com & 0-2000 (L, M) & $1,2,4,6$ & $\mathrm{~A}, \mathrm{~B} *, \mathrm{~B}(?)$ & $\begin{array}{c}\text { Terres- } \\
\text { trial }\end{array}$ & Small & Ins/vert & $\begin{array}{c}\text { Near- } \\
\text { T. }\end{array}$ \\
\hline $\begin{array}{c}\text { Ispidina } \\
\text { madagascariensis }\end{array}$ & 0.5 & Com & 0-1800 (L, M) & $1,2,5,6$ & $A, C$ & $\begin{array}{c}\text { Terres- } \\
\text { trial }\end{array}$ & Small & Invert/vert & - \\
\hline
\end{tabular}


Appendix B. Contd....

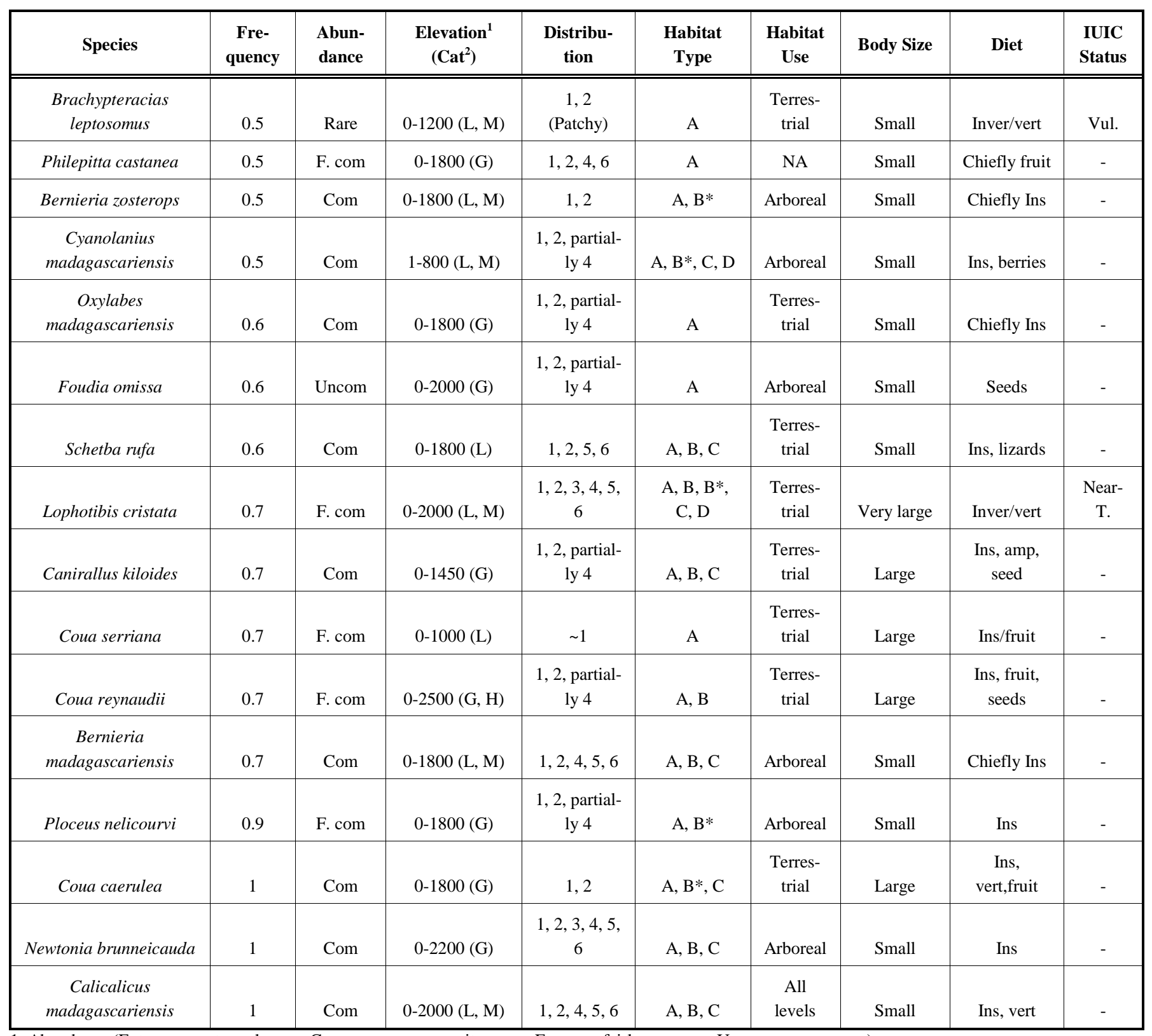

1. Abundance (Ext. rare = extremely rare; Com = common over its range; F. com = fairly common; Uncom = uncommon)

2. Distribution ( $1=$ North east; $2=$ South east; $3=$ South center; $4=$ North center; $5=$ South west; $6=$ North west)

3. Body size (Very large R: $40 \mathrm{~cm}$, Raptors; Large R: 28-39 cm, Raptors; Small $\leq 28 \mathrm{~cm}$ )

4. Diet (ins = insects; rep = reptiles; lem = lemurs; amp = amphibians; inver $=$ invertebrates; vert $=$ vertebrates)

5. Habitat type (A = Undisturbed rainforest; B = Secondary growth; $\mathrm{B}^{*}=$ Adjacent secondary growth; $\mathrm{C}=$ Deciduous dry forest; $\mathrm{D}=$ Mangrove)

6. Threat status (Crit. End. $=$ Critically endangered; Vul. $=$ Vulnerable; Near-T. $=$ Near-threatened)

${ }^{1}$ from Langrand [2]; ${ }^{2}$ categories identified by Hawkins [4], $L=$ low elevation, $M=$ mid elevation, $H=$ high elevation, $G=$ elevation generalist; ? = indeterminate

\section{REFERENCES}

[1] Laurance WF, Bierregaard RO, Eds. Tropical forest remnants: ecology, management, and conservation of fragmented communities. Illinois: The University of Chicago Press 1997.

[2] Langrand O. Guide to the Birds of Madagascar. Connecticut: Yale University Press 1990.

[3] Hawkins AFA, Goodman SM. In: Goodman SM, Benstead JP, Eds. The natural history of Madagascar. Illinois; The University of Chicago Press 2003; pp. 1019-44.

[4] Hawkins AFA. Altitudinal and latitudinal distribution of east Malagasy forest bird communities. J Biogeogr 1999; 26: 447-58.
[5] Harper GJ, Steininger MK, Tucker CJ, Juhn D, Hawkins AFA Fifty years of deforestation and forest fragmentation in Madagascar. Environ Conserv 2007; 34: 325-33.

[6] Green GM, Sussman RW. Deforestation history of the eastern rain forests of Madagascar from satellite images. Science 1990; 248: 212-5.

[7] Langrand O, Wilmé L. In: Goodman SM, Patterson BD, Eds. Natural change and human impact in Madagascar. Washington, DC: Smithsonian Institution Press 1997; pp. 280-305.

[8] Raherilalao MJ. Effets de la fragmentation de la forêt sur les oiseaux autour du Parc National de Ranomafana (Madagascar). Rév Ecol 2001; 56: 389-406. 
[9] Watson JEM, Whittaker RJ, Dawson TP. Avifaunal responses to habitat fragmentation in the threatened littoral forests of southeastern Madagascar. J Biogeogr 2004; 31: 1791-807.

[10] Andriamasimanana RH, Rabenandrasana MN, Raminoarisoa V, et $a l$. Effets de la fragmentation de la forêt humide sur les populations d'oiseaux et de lémuriens dans le corridor Mantadia-Zahamena. Lemur News 2001; 6: 18-22.

[11] UNFPA [homepage on the internet]. State of World Population. United Nations Population Fund, New York. [Accessed 2013 April 15; cited 2013 April 15]. Available from: http://www.unfpa.org/swp/2009/en/pdf/EN_SOWP09.pdf.

[12] Patterson BD, Atmar W. Nested subsets and the structure of insular mammalian faunas and archipelagos. Biol J Linn Soc 1986; 28: 6582.

[13] Atmar W, Patterson BD. The measure of order and disorder in the distribution of species in a fragmented habitat. Oecologia 1993; 96: 373-82.

[14] Patterson BD, Atmar W. In: Rheinwald G, Ed. Isolated vertebrate communities in the tropics. Bonn Zool Monogr 46. Bonn: Museum Alexander Koenig 2000; pp. 9-24.

[15] Ganzhorn JU, Eisenbeiß B. The concept of nested species assemblages and its utility for understanding effects of habitat fragmentation. Basic Appl Ecol 2001; 2: 87-95.

[16] Connor EF, McCoy ED. In: Levin SA, Ed. Encyclopedia of biodiversity. vol 5. San Diego: Academic Press 2001; pp. 397-411.

[17] Lomolino MV. The species-area relationship: new challenges for an old pattern. Prog Phys Geogr 2001; 25: 1-21.

[18] Connor EF, McCoy ED. The statistics and biology of the speciesarea relationship. Am Nat 1979; 113: 791-833.

[19] Diamond JM. In: Soulé ME, Wilcox BA, Eds. Conservation biology: an ecological-evolutionary perspective. Massachusetts: Sinauer Associates Inc. 1980; pp. 57-74.

[20] Avibase [homepage on the internet]. The world bird database. [Accessed 2013 April 15; cited 2013 April 15]. Available from http://avibase.bsc-eoc.org/checklist.jsp?lang=EN.

[21] Wilmé L. In: Lourenco WR, Ed. Biogéographie de Madagascar. Paris: Editions de I'ORSTOM 1996; pp. 349-62.

[22] Wilmé L, Goodman SM. Biogeography, guild structure, and elevational variation of Madagascar forest birds. In: Goodman SM, Benstead JP, Eds. The natural history of Madagascar. Chicago: The University of Chicago Press 2003; pp. 1045-58.

[23] DuPuy DJ, Moat JF. In: Huxley CR, Lockand JM, Cutler DF, Eds. Chorology, taxonomy and ecology of the Floras of Africa and Madagascar. Kew: Royal Botanic Gardens 1998; pp. 97-117.

[24] Collar NJ, Crosby MJ, Stattersfield AJ. Birds to Watch 2: The world list of threatened birds. Birdlife Conservation Series No. 4. Cambridge, UK: Birdlife International 1994.

[25] Thorstrom R, René de Roland L-A [a]. In: Goodman SM, Benstead JP, Eds. The natural history of Madagascar. Chicago: The University of Chicago Press 2003; pp. 1088-91.

[26] Thorstrom R, René de Roland L-A [b]. In: Goodman SM, Benstead JP, Eds. The natural history of Madagascar. Chicago: The Universitry of Chicago Press 2003; pp. 1110-13.

[27] International Resources Group Ltd [homepage on the internet]. Effets de la fragmentation de forêt humide sur les populations des oiseaux et des lémuriens dans le corridor Mantadia-Zahamena. ZICOMA final report 2000. [Accessed 2013 January 28; cited 2013 January 28]. Available from: http://rmportal.net/library/content/ tools/environmental-policy-and-institutional-strengthening-epiqiqc/epiq-environmental-policy-and-institutional-strengthening-cdvol-1/epiq-cd-1-tech-area-biodiversity-conservation/effets-de-lafragmentation-de-foret-humide-sur-les-populations-

french/view?searchterm=Madagascarhttp://www.irgltd.com/Engilit y.html

[28] Schmid J, Alonso LE, Eds. Une évaluation biologique rapide du corridor Mantadia-Zahamena à Madagascar. Bulletin RAP d'Evaluation Rapide 32. Washington, DC: Conservation International 2005.

[29] Hawkins AFA. Ornithological inventory and survey. Zahamena Reserve Project. Report to Conservation International 1995.

[30] MacKinnon J, Phillips K. A field guide to the birds of Borneo, Sumatra, Java and Bali, the Greater Sunda Islands. Oxford: Oxford University Press 1993.

[31] Bibby C, Burgess N, Hill D, Mustoe S. Bird census techniques. London: Academic Press 2000.
[32] MacLeod R, Herzog SK, Maccormick A, Ewing SR, Bryce R, Evans KL. Rapid monitoring of species abundance for biodiversity conservation: consistency and reliability of the MacKinnon lists technique. Biol Conserv 2011; 144: 1374-81.

[33] BirdLife International [homepage on the internet]. IUCN Red List for birds. [Accessed 2013 February 10; cited 2013 February 10]. Available from: http://www.birdlife.org

[34] Rabinowitz D, Cairns S, Dillon T. In: Soulé ME, Ed. Conservation biology: the science of scarcity and diversity. Massachusetts: Sinauer Associates Inc. 1986; pp. 182-204.

[35] Bray JR, Curtis JT. An ordination of the upland forest communities of Southern Wisconsin. Ecol Monogr 1957; 27: 325-49.

[36] McCune B, Grace JB. Analysis of ecological communities. Oregon: MjM Software Design 2002.

[37] Oksanen J, Blanchet G, Kindt R, et al. Community Ecology Package. 2011. R package Version 2.0-2. Available at: http://cran.rproject.org/.

[38] Moran, PAP. Notes on continuous stochastic phenomena, Biometrika 1950; 37: 17-23.

[39] Cook, RD. Detection of influential observations in linear regression". Technometrics (American Statistical Association) 1977; 19: 15-8.

[40] SAS Institute Inc. SAS ${ }^{\circledR} 9.3$ System Options: Reference, Second Edition. Cary, NC: SAS Institute Inc. 2011.

[41] Benjamini Y, Hochberg Y. Controlling the false discovery rate: a practical and powerful approach to multiple testing. J R Stat Soc Ser B (Methodological) 1995; 57: 289-300.

[42] Pike N. Using false discovery rates for multiple comparisons in ecology and evolution. Methods Ecol Evol [serial on the Internet]. 2013 April 15; [cited 2013 April 15]; 329: [about 10 screens]. Available from: http://onlinelibrary.wiley.com/doi/10.1111/j.2041210X.2010.00061.x/abstract

[43] Ulrich W, Gotelli NJ [a]. Null model analysis of species nestedness patterns. Ecology 2007; 88: 1824-31.

[44] Ulrich W, Gotelli NJ [b]. Disentangling community patterns of nestedness and species co-occurrence. Oikos 2007; 116: 2053-61.

[45] Ulrich W, Almeida-Neto M, Gotelli NG. A consumer's guide to nestedness analysis. Oikos 2009; 118: 3-17.

[46] Brualdi RA, Sanderson JG. Nested species subsets, gaps, and discrepancy. Oecologia 1999; 119: 256-64.

[47] Almeida-Neto M, Guimarães P, Guimarães PR Jr, Loyola RD, Ulrich W. A consistent metric for nestedness analysis in ecological systems: reconciling concept and quantification. Oikos 2008; 117: 1227-39.

[48] Ulrich W. Nestedness analysis as a tool to identify ecological gradients. Ecol Questions 2009: 11; 27-34.

[49] Almeida-Neto M, Ulrich W. A straightforward computational approach for measuring nestedness using quantitative matrices. Environ Model Softw 2011; 26: 173-8.

[50] Rakotoarisoa J-E, Be B. Breeding and foraging behaviour and habitat characteristics of the Scaly Ground-roller Geobiastes squamigerus in Madagascar. Ostrich 2004; 75: 25-31.

[51] Terborgh J, Winter B. In: Soulé ME, Wilcox BA, Eds. Conservation biology: an ecological -evolutionary perspective. Massachusetts: Sinauer Associates Inc. 1980; pp. 119-133.

[52] Newmark WD. Tropical forest fragmentation and the local extinction of understory birds in the Eastern Usambara Mountains, Tanzania. Conserv Biol 1991; 5: 67-78.

[53] Kattan G, Alvarez-López H, Giraldo M. Forest fragmentation and bird extinctions: San Antonio eighty years later. Conserv Biol 1994; 8: 138-46.

[54] Bierregaard RO, Gascon C Jr, Lovejoy TE, Mesquita R, Eds. Lessons from Amazonia: the ecology and conservation of a fragmented Forest. Connecticut: Yale University Press 2001.

[55] Zanette L, Doyle P, Trémont SM. Food shortage in small fragments: evidence from an area-sensitive passerine. Ecology 2000; 8: 1654-66.

[56] Karr J, Freemark K. Habitat selection and environmental gradients: dynamics in the "stable" tropics. Ecology 1983; 64: 1481-94.

[57] Canaday C. Loss of insectivorous birds along a gradient of human impact in Amazonia. Biol Conserv 1996; 77: 63-77.

[58] Ford HA, Barrett GW, Saunders DA, Recher HF. Why have birds in the woodlands of Southern Australia declined? Biol Conserv 2001; 97: 71-88. 
[59] Hart DD, Horwitz RJ. In: Bell SS, McCoy ED, Mushinsky HR, Eds. Habitat structure: the physical arrangement of objects in space. London: Chapman and Hall 1991; pp. 47-68.

[60] Weinberg HJ, Roth RR. Forest area and habitat quality for nesting wood thrushes. Auk 1998; 115: 879-89.

[61] Brown KA, Gurevitch J. Long-term impacts of logging on forest diversity in Madagascar. Proc Natl Acad Sci USA 2004; 101: 6045-9.

[62] Barrett MA, Brown JL, Morikawa MK, Labat JN, Yoder AD. CITES designation for endangered rosewood in Madagascar. Science 2010; 328: 1109-10.

[63] Randriamalala H, Liu Z. Rosewood of Madagascar: between democracy and conservation. Madagas Conserv Dev 2010; 5: 11-22.

[64] Hu G, Feeley KJ, Wu J, Xu G, Yu M. Determinants of plant species richness and patterns of nestedness in fragmented landscapes: evidence from land-bridge islands. Landsc Ecol 2011; 26: 1405-17.

[65] Ganzhorn JU, Goodman SM, Ramanamanjato J-B, Ralison J, Rakotondravony D, Rakotosamimanana B. In: Rheinwald G, Ed.
Isolated vertebrate communities in the tropics. Bonn zool Monogr 46. Bonn: Museum Alexander Koenig 2000; pp. 265-72.

[66] Hecnar SJ, Casper GS, Russell RW, Hecnar DR, Robinson JN. Nested species assemblages of amphibians and reptiles on islands in the Laurentian Great Lakes. J Biogeogr 2002; 29: 475-89.

[67] Wang Y, Wang X, Ding P. Nestedness of snake assemblages on islands of an inundated lake. Curr Zool 2012; 58: 828-36.

[68] Stratford JA, Stouffer PC. Local extinctions of terrestrial insectivorous birds in a fragmented landscape near Manaus, Brazil. Conserv Biol 1999; 13: 1416-23.

[69] Almeida-Neto M, Guimarães PR Jr, Lewinsohn TM. On nestedness analyses: rethinking matrix temperature and anti-nestedness. Oikos 2007; 116: 716-22.

[70] Gotelli NJ, Colwell RK. Quantifying biodiversity: procedures and pitfalls in the measurement and comparison of Great Lakes. J Biogeogr 2001; 29: 475-89.

[71] Loiselle P, Rabeson P, Raharison J-L, et al. Patterns of species change in anthropogenically disturbed forests of Madagascar. Biol Conserv 2010; 143: 2351-62.

(c) Rakotoarisoa and Capparella; Licensee Bentham Open.

This is an open access article licensed under the terms of the Creative Commons Attribution Non-Commercial License (http://creativecommons.org/licenses/by-nc/3.0/) which permits unrestricted, non-commercial use, distribution and reproduction in any medium, provided the work is properly cited. 